folium, Geranium, Sedum, \&c. The forests which clothe the banks of the Jenissei consist to a great extent of nonScandinavian trees, namely, of the larch, Pinzes cembra, Abies sibirica, and the Abies obovate, which scarcely differs from Pinus abies, and of Populus nigra. Of the trees common to Scandinavia the most important are the birch (Betula verrucosa and glutinosa), pine, aspen, bird's cherry, and mountain ash. Besides, the Salices play a very important part on the Jenissei, inasmuch as they form extensive woods on the low banks periodically overflowed; these Salices often grow to uncommonly large sizes, and consist in part of non-Scandinavian species, one of which, Salix vitellina, is the most common of all, and spreads over the whole of the region examined by the botanists of the expedition.

The bush vegetation too in Siberia exhibits differences from that of Scandinavia. On the Jenissei Alnaster fruiticosies is important beyond others, because it forms thickets, and especially towards the north increases in mass, going in that direction beyond the limit of trees. Among other bushes foreign to our flora there occur on the Jenissei the Siberian pea tree (Robinia), Spirce confusa, sorbifolia and salicifolia, Sambucus racemosa, Cratagus sanguined, Cassandra calyculato, peculiar types of roses, \&c. Among the bushes common to Scandinavia the most important are the black and red currant, dwarf birch, Lonicera corulea, which is far more widely distributed than in Sweden, juniper, Myrica gale, raspberry, Empetrum nigrum, Vaccinium vitis idac, and myrtillus, \&c. Towards the north the bushy Salices play an important part, as in our northern regions. On the Jenissei there has been found only one species of $A$ lnzks, which is specially interesting as not being either of the Swedish species, but perhaps the genuine Alnuts pubescens. On the other hand there are absent on the Jenissei many of our trees and bushes, as the nobler deciduous trees and fruit trees, and, what may be said to be distinctive of the Jenissei flora, heather, which is so extensively distributed in Sweden, is wanting.

\section{TEMPERATURE AND HUMIDITY OF THE} AIR AT DIFFERENT HEIGHTS

$A$ MEMOIR on the temperature and humidity A of the air at different hours, by Dr. H. E. Hamberg, based on observations made by him during the summer of 1875 , at heights varying from 2 inches to 22 feet above the ground, was published recently in the Transactions of the Royal Society of Sciences at Upsal. The memoir is a valuable one, and is of interest to more than the mere meteorologist, it being evident that the inquiry is so handled as to bring it into close connection with such difficult questions as convection currents in the free atmosphere and the diffusion of vapour through the air.

In clear weather the temperature of the air nearest the surface was lower than that above it, from two to three hours before sunset to at least two to three hours after sunrise. At all the six heights the temperature fell to the minimum at the same hour, viz., about 3 A.M. ; but while it continued from this time to rise steadily at all the heights, the lowest temperatures continued to be observed in the strata nearest the ground till several hours after sunrise. From this remarkable result Dr. Hamberg concludes that the increase of temperature in the lower strata of the air in the early part of the forenoon is not an immediate and direct consequence of the heating of the ground, but is rather to be attributed to the absorption by the air, or more strictly by its aqueous vapour, of the heat received from the sun's rays or reflected from the ground.

Over uneven ground covered with vegetation the temperature near the surface is generally higher over those parts of the field which rise above the general level. Thus even slight elevations of only one or two feet have the air immediately resting on them often $2^{\circ}$ higher or mure, whilst on the other hand, a trench or depression one or two feet below the general level has the air resting on it often $2^{\circ}$, or more, lower than the air over the level portions of the field, a result of considerable practical importance in agriculture and horticulture.

The latent heat set free on the formation of dew appears from the observations clearly to retard the lowering of the temperature, but not to the extent which might have been expected. When, on the deposition of dew, the temperature of the air near the surface has fallen below $32^{\circ}$, as soon as the dew is congealed into hoar-frost the temperature of the lowest stratum of air in contact with the ground instantly rises to $32^{\circ}$; but at the same time the temperature of the air higher up steadily remains lower than $32^{\circ}$.

The absolute humidity of the air on clear nights on which no dew is deposited decreases from the ground upwards, just as happens during the day; but on the other hand, with dew, the humidity is least nearest the ground, and increases with the height, and this influence of dew, in diminishing the humidity, extends lupwards to at least twenty-two feet, the height to which the observations were carried. Since his observations clearly show that the absolute humidity begins in the evening to diminish near the ground before any dew is observed to be deposited, and also diminishes at all heights on those nights during which no dew whatever is formed, Dr. Hamberg is of opinion that the diminution of the humidity of the air during night is to be sought for in other physical causes than the deposition of dew.

Several of the points discussed will doubtless be made subjects of further investigation by others. In all cases it is most desirable, indeed absolutely necessary, to a critical valuation of the observations, that the authors give woodcuts and descriptions of the exact position and mode of protection adopted in the case of each thermometer employed in the observations. For such refined inquiries the method of observation must necessarily be a refined one ; in other words, such as will certainly secure the necessary comparability among all the instruments.

THE CHRONOMETERS OF SWITZERLAND

$W^{E}$ find in a recent number of the Bulletin of the Society of Natural Sciences at Neuchâtel an interesting report of the Neuchâtel Observatory on the annual competition of chronometers for prizes awarded yearly by the Observatory. The report gives some idea of the degree of perfection reached in Switzerland in the construction of chronometers. The 231 chronometers (four box and 227 pocket chronometers) admitted to the competition out of 270 sent in were submitted to a severe test, including changes of temperature and of position during periods of from two weeks to two months, and the results of the trial appear as follows. The average diurnal variations in the rates of the box-chronometers proved $0^{\circ} 32$ sec. (against $0^{\circ} 20$ in 1874 ), and of the pocleet ones 0.46 sec. (against 0.53 in 1874), and there was but two per cent. of these last, the average diurnal variation of which reached I sec. The various systems of escapements appeared, as was observed in former years, to have but little if any influence on the degree of precision of watches, provided they remain constantly in the same position, vertical or horizontal. The compensation for changes of temperature proved to bealtogether satisfactory, the average variation of 167 chronometers submitted to variations of temperature from I 5 to 25 Cent. degrees being but $0^{\prime} I 3$ sec. for each Centigrade degree. It must, however, be noticed that only 5 I per cent. of them showed variations below one-tenth of a second for each degree, and that to per cent. showed variations above $0^{\circ} 3 \mathrm{sec}$. Finally, the differences between the rates during the first and the last weeks were: for box-chronometers, 2 I I sec. 
after a period of two months; and for pocket-chronometers, 1.57 sec. after a trial of six weeks; and the average differences between the maximum and minimum rates proved to be, for box-chronometers, $3^{*} 23 \mathrm{sec}$, after a two months' trial ; and for pocket-chronometers, $6.22 \mathrm{sec}$. and 5.75 after six weeks and one month's trials. These figures show certainly that there is enough to do yet in raising the industry to the high degree of perfection which is desirable, but the steady progress during the last ten years is remarkably seen in a table showing the increase of precision of the Swiss chronometers in every direction. Thus the average diurnal variation, which was as high as $1.27 \mathrm{sec}$. at the competition of 1864 , regularly decreases to 0.46 in 1875 ; the average variations of rate produced by changes of position, being $8.2 \mathrm{I}$ sec. ten years ago, is now but I' 97 ; and the defective compensation for temperature rapidly decreases from $0.48 \mathrm{sec}$. for each degree to $0^{\prime} 16$, and now it is but $0^{\circ} 13$. Besides, the report states, some of the best chronometers reach as high a degree of perfection as to make them comparable with astronomical clocks. Thus the box-chronometer which received the first prize is a true phenomenon of its kind. Its mean diurnal variation is as low as $0.08 \mathrm{sec}$, i.e., that of good astronomical clocks ; its mean weekly rate changed after a two months' trial only by $0.57 \mathrm{sec}$; the difference between the maximum and minimum rates is but $0^{\prime} 94 \mathrm{sec}$., and the imperfect compensation for temperature is 0.04 sec. for each degree; finally, its characteristic number, calculated by the Greenwich method, reaches but 8.90 sec. The two best pocket-chronometers realise perhaps a yet greater success, their average diurnal variations being respectively bit $0^{\circ} 13$ and $0^{\circ} 17 \mathrm{sec}$.

\section{THE BRITISH ASSOCIATION}

$\mathrm{T}$ $\mathrm{E}$ two soirées that were held in the Guildhall, the first on the evening of Thursday, the I6th instant and the second on Tuesday, the $2 \mathrm{Ist}$, were very fully attended.

At the second conversazione several objects of scientific interest were exhibited. At the centre table Prof. Herbert Mcleod showed his beautiful cycloscope, an instrument which formed the subject of a paper read by Prof. McLeod before Section $G$ on Wednesday week. Mr. Silvanus P. Thompson, of University College, Bristol, showed his apparatus for exhibiting certain optical illusions, upon which a paper was read by him in Section A. Prof. Osborne Reynolds showed the apparatus by which his paper upon the rate of progression of groups of waves was illustrated; and Mr. J. W. Swan exhibited a modifcation of the Sprengel pump.

In the picture gallery Dr. Graham Bell had his articulating telephones at work.

There was great competition for the tickets for the excursions for both Saturday and Thursday. The excursion to Lee Moor under the guidance of Mr. Spence Bate, F.R.S., was originally limited to 100 , but there were more than 300 applications for tickets, and extra waggonettes had to be put on. The party, after having visited the China Clay Works of Messrs. Martin, the largest establishment of its kind in the world, divided into three parties: the first walked across the Moor to Sheepston, to examine some prehistoric remains recently discovered by $\mathrm{Mr}$. Spence Bate. Another party under the charge of Mr. Martin took a walk to Shell top and Pen Beacon, from which fine views may be had; and a third detachment remained in the grounds of Mr. Martin, which are unique in their way, from the intricacy of their laying out.

The popular excursion of the day was, however, that up the Hamoaze and Tamar, to H.M.S. Cambridge, under Great Albert Bridge at Saltash, into the Sound, and visiting the Breakwater and Eddystone Lighthouse.
The Admiral of the Port placed three Government steamers at the disposal of the Association, and there was tremendous crowding to get on to the boats. Upon reaching H.M.'s gunnery ship Cambridoe, the gunnery and torpedo practice began, and some splendid feats of fring at long ranges were exhibited.

On the same day there was a dredging excursion uncier the superintendence of Mr. Gwyn Jeffreys and Mr. Hearder.

While these excursions were going on a select party was, at the invitation of the Mayor and Corporation of Exeter, visiting that ancient city. At the luncheon, the toast of "The British Association," was proposed by Sir Stafford Northcote, Chancellor of the Exchequer, and responded to by Mr. Spottiswoode, F.R.S., the President-elect.

The excursions on Thursday last were first to Liskeard, the Cheesewring, and the Caradons, at the invitation of the Mayor of Liskeard. The second excursion was by way of the Tamar to Morwellham to the celebrated Devon Consols Copper Mines, taking on its way the fine old mediaval mansion of Cotehele, which was thrown open to the members by the Earl of Mount Edgcumbe, to whom it belongs. The last of Thursday's excursions was to Totnes, Torquay, and Brixham, and like the Exeter excursion, was only by special invitation. It was divided into four sub-excursions (a), Archæological, visiting Totnes and Befry Pomeroy Castles; (b), Mechanical, visiting the Experimental Works of Mr. Froude, F.R.S.; and ( $c$ and $d$ ), Antiquarian and Geological, the first to Kent's Cavern, under the guidance of Mr. Vivian, and the second to Brixham, with Mr. Pengelly, F.R.S.

The Plymouth meeting of the British Association for 1877 has been decidedly a quiet one; its attendance as a whole has been below the average, and its funds are proportionately low ; but it has done good work, and it has been marked by several papers of great scientific interest. The discovery by Prof. J. C. Adams of the original papers of Newton respecting the rotation of the apse of the moon, the exhibition of the articulating telephone of Dr. Graham Bell and the very valuable suggestions contained in the address of Prof. Carey Foster, must all help to mark the Plymouth meeting in the annals of the Association as a valuable one, notwithstanding its failure in points of attendance and pecuniary position.

The following are some of the figures connected with the recent meeting :-

\begin{tabular}{|c|c|c|c|c|c|c|c|}
\hline Numbe & f tick & ssue & Old Life $M$ & Aembers & & & $16 I$ \\
\hline$"$ & , & $"$ & New, , & & & $\ldots$ & \\
\hline ", & " & " & Old Annua & al Subscr & eriber & & \\
\hline , & ", & ", & New ,, & $"$ & & $\ldots$ & \\
\hline " & " & , & Associates & $\ldots$ & $\cdots$ & $\cdots$ & \\
\hline There & e alsc & sent & $\begin{array}{l}\text { Ladies } \\
\text { Foreign }\end{array}$ & embers & $\begin{array}{l}\ldots \\
\ldots\end{array}$ & $\ldots$ & \\
\hline
\end{tabular}

The total receipts from the sale of tickets amounted to I, $267 l$.

\section{REPORTS.}

Prof. O. Reynolds presented the Report of the Committee $a p$. pointed to consider what Effect Reversing the Screw had on the Steering of a Steamer under Full Way.--Since the last meeting of the Association the Committee had carried out further experiments, and the results now obtained show that the larger the ship the more important the effect of reversing the screw became. In answer to the request of the Committee, the Admiralty had made a trial with H.M.S. Speedy, but the conditions under which it was conducted precluded the possibility of more light being thrown on the subject. The greatest speed was five knots, and the effect of the rudder with the screw reversed was so small that the vessel in most instances turned her forward end into the wind. The Admiralty had been urged to have experiments made with larger and more powerful ships, but as yet had not assented. 